\title{
SOLUSI PERSAMAAN DIFERENSIAL PADA SISTEM \\ BEJANA DENGAN MENGGUNAKAN METODE TRANSFORMASI LAPLACE
}

\author{
Risnawati Ibnas ${ }^{1}$, Putri Resky Hasyim ${ }^{1}$, Muhammad Ridwan ${ }^{1}$ \\ ${ }^{1}$ Prodi Matematika UIN Alauddin Makassar \\ E-mail: risnawati.ibnas@uin-alauddin.ac.id
}

\begin{abstract}
The purpose of this study is to obtain the results of the completion of the Differential Equations in the Vessel System using the Laplace Transform Method. advantage of the Laplace transform is that the initial value problem of a linear differential equation can be solved directly without first determining the general solution and also to obtain the maximum benefit. The model that has been obtained in-vessel systems is homogeneous nonlinear differential equation:
\end{abstract}

$$
\frac{d^{2} h_{2}(t)}{d t^{2}}+2 \xi \omega \frac{d h_{2}(t)}{d t}+\omega^{2} h_{2}(t)=0
$$

if we want to obtain total we must be taken aggregate from a general solution and special solution, the result is

$h_{t}=c_{1} e^{\left(-\xi \omega+\omega \sqrt{\xi^{2}-1}\right) t}+c_{2} e^{\left(-\xi \omega-\omega \sqrt{\xi^{2}}-1\right) t}+t e^{-\omega t}$

Keywords: Differential equation, Vessel System, Laplace Transformation

\section{PENDAHULUAN}

$\mathrm{P}$ ersamaan diferensial merupakan persamaan yang berkaitan dengan turunan suatu fungsi atau memuat suku-suku dari fungsi tersebut dan turunannya. Pada dasarnya persamaan diferensial dibagi menjadi dua, yaitu Persamaan Diferensial Biasa (PDB) dan Persamaan Diferensial Parsial (PDP). Banyak permasalahan yang muncul dalam persamaan diferensial maka dibutuhkan beberapa metode dalam menyelesaikan masalah tersebut. Persamaan diferensial dapat diselesaikan dengan cara analitik seperti pemakaian transformasi, penggunaan subtitusi, dan penggunaan konstanta sembarang. Namun, penyelesaian yang sering ditemukan adalah penyelesaian diferensial linear. Kenyataannya permasalahan yang banyak ditemukan adalah bukan hanya persamaan diferensial linear melainkan permasalahan persamaan diferensial non linear, salah satu contohnya yaitu pada sistem bendungan. Khususnya sistem bendungan yang terdiri dari dua bendungan, dimana bendungan yang satu terletak dibawah bendungan yang lain. Dalam penelitian ini bendungan diasumsikan sebagai bejana, karena bejana mempunyai kesamaan fisik dengan bendungan. Walaupun pada kenyataannya pada bentuk bendungan tidak teratur.

Bejana merupakan benda berongga yang bisa diisi dengan berbagai jenis cairan atau serbuk dan pada umumnya digunakan sebagai wadah,tabung,dan sebagainya. Bejana terdiri dari beberpa jenis, salah satunya adalah bejana berhubungan. Bejana berhubungan yaitu beberapa bejana yang saling terhubung dan berisi cairan homogen. 
Salah satu metode untuk memperoleh solusi dari model matematika tersebut adalah Metode Transformasi Laplace. Metode Transformasi Laplace (Laplace Transformation) merupakan salah satu metode yang digunakan untuk menyelesaikan persamaan diferensial.

\section{METODE PENELITIAN}

Metode yang digunakan menyelesaikan persamaan diferensial pada Sistem Bejana dengan menggunakan metode Transformasi Laplace dengan tahapan sebagai berikut : (1) Membentuk model atau persamaan diferensial tak linear homogen pada sistem bejana, (2) Mengkonstrusinya ke bentuk Transformasi Laplace kemudian menggunakan metode Transformasi Laplace dengan bentuk yaitu $H(s)=L\left\{h_{2}(t)\right\}=\int_{0}^{\infty} e^{-s t} h_{2}(t) d t$, (3) Menentukan solusi umum $h_{2}(t)$, persamaan diferensial tak linear homogen dari model sistem bejana, dengan syarat Peredam Berlebihan jika $\xi>1$, Peredam Kritis jika $\xi=1$ dan Peredam Berkurang jika $0<\xi<1$ (4) Menentukan solusi total $h_{t}$ dari penggabungan solusi umum $h_{2}(t)$ dengan solusi khusus $h_{p}, h_{t}=h_{2}(t)+h_{p}$ dan Membuat grafik dari solusi total $h_{t}$, solusi umum $h_{2}(t)$, dan solusi khusus $h_{p}$.

\section{HASIL DAN PEMBAHASAN}

\section{A. HASIL}

Untuk mendapatkan solusi dari sistem bendungan yang diasumsikan sebagai bejana khususnya sistem bejana yang terdiri dari dua bejana, dimana bejana yang satu terletak dari bejana yang lain, maka diperoleh gambar seperti di bawah ini:

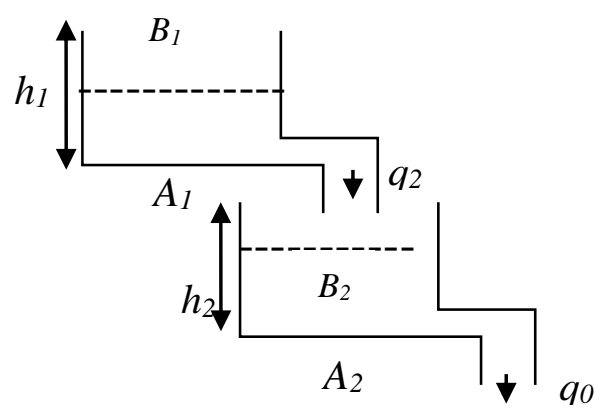

Dimana:

$B_{1}$ : Bejana yang terletak di atas

$B_{2}$ : Bejana yang terletak di bawah

$h_{l}$ : Tinggi air pada $B_{l}(m)$

$h_{2}$ : Tinggi air pada $B_{2}(m)$

$q_{0}$ : Aliran air yang keluar dari $B_{2}\left(m^{3} s^{-1}\right)$ 
$q_{2}$ : Aliran air yang keluar dari $B_{1}$ dan masuk pada $B_{2}\left(m^{3} s^{-1}\right)$

$A_{l}$ : Luas penampang yang memuat air pada sistem $B_{l}\left(\mathrm{~m}^{2}\right)$

$A_{2}$ : Luas penampang yang memuat air pada sistem $B_{2}\left(\mathrm{~m}^{2}\right)$

Model yang telah didapatkanpada sistem bejana adalah

$\frac{d^{2} h_{2}(t)}{d t^{2}}+2 \xi \omega_{n} \frac{d h_{2}(t)}{d t}+\omega_{n}{ }^{2} h_{2}(t)=0$

dimana :

$\alpha$ : Rasio Peredam

$\beta$ : Frekuensi Alami

$h_{2}$ :Tinggi air pada sistem $B_{2}(m)$

$t:$ waktu

Pada Persamaan tersebut terdapat tiga kasus, yaitu:

1. Kasus Peredam Berlebihan $(\xi>1)$

Bentuk solusi umumnya adalah

$$
h_{2}(t)=c_{1} e^{x_{1} t}+c_{2} e^{x_{2} t}
$$

Pada Persamaan (4.1) menyatakan tinggi air pada $B_{2}$ saat $t$ yang menunjukkan laju volume air bertambah. Sehingga semakin besar laju volume air pada $B_{2}$ maka semakin besar tinggi peningkatan air.

Solusi umumnya dengan mencari karakteristik

misalkan:

$$
\begin{aligned}
& h_{2}(t)=e^{x t} \\
& \frac{d h_{2}(t)}{d t}=x e^{x t} \\
& \frac{d^{2} h_{2}(t)}{d t^{2}}=x^{2} e^{x t}
\end{aligned}
$$

Maka

$$
\begin{aligned}
& x^{2} e^{x t}+2 \xi \omega x e^{x t}+\omega^{2} e^{x t}=0 \\
& e^{x t}\left(x^{2}+2 \xi \omega x+\omega^{2}\right)=0 \text { dengan } e^{x t} \neq 0, \text { maka } \\
& x^{2}+2 \xi \omega x+\omega^{2}=0
\end{aligned}
$$

Persamaan (4.5) adalah Persamaan karakteristik.

Akar-akar karakteristik dari Persamaan (4.5) dengan menggunakan rumus abc, maka diperoleh :

$$
x_{1}=\left(-\xi \omega+\omega \sqrt{\xi^{2}-1}\right) \text { atau } x_{2}=\left(-\xi \omega-\omega \sqrt{\xi^{2}-1}\right)
$$

maka solusi umumnya yaitu :

$$
h_{2}(t)=c_{1} e^{\left(-\xi \omega+\omega \sqrt{\xi^{2}-1}\right) t}+c_{2} e^{\left(-\xi \omega-\omega \sqrt{\xi^{2}}-1\right) t}
$$

Persamaan (4.7) menyatakan tinggi air pada bejana $B_{2}$ saat $t$.

Dengan $c_{1}, c_{2}$ adalah konstanta, yang nilainya kedua konstanta tersebut bergantung 
dari $h_{2}(0)$ dan $\frac{d h_{2}(0)}{d t}$,

maka diperoleh $c_{1}$ dan $c_{2}$ adalah sebagai berikut.

$$
c_{1}=\left(\frac{\left(\frac{B_{2}}{\omega}\right)+\left(\xi+\sqrt{\xi^{2}-1}\right)}{-\xi+\sqrt{\xi^{2}-1}}\right) \text { dan } c_{2}=A_{2}-\frac{\left(\frac{B_{2}}{\omega}\right)+\left(\xi+\sqrt{\xi^{2}-1}\right)}{-\xi+\sqrt{\xi^{2}-1}}
$$

Sehingga untuk $t \rightarrow \infty$ maka $h_{2}(t) \rightarrow 0$ dan $V_{2}(t) \rightarrow 0$, yang berarti untuk jangka waktu yang lama. Maka tidak ada air pada bejana $B_{2}$.

Jika transformasi laplace adalah $H(s)=L\left\{h_{2}(t)\right\}=\int_{0}^{\infty} e^{-s t} h_{2}(t) d t$, maka transformasi laplace dari turunan pertama adalah $L\left(\frac{d h_{2} t}{d t}\right)=\int_{0}^{\infty} e^{-s t}\left(\frac{d h_{2} t}{d t}\right) d t$. pada Persamaan (4.8) dimisalkan u adalah $e^{-s t}$ dan $v$ adalah $h_{2}(t)$, maka

$$
L\left(\frac{d h_{2}(t)}{d t}\right)=\left[\left(e^{-s t} h_{2}(t)\right)\right]_{0}^{\infty}+\left(s \int_{0}^{\infty} e^{-s t} h_{2}(t) d t\right)
$$

Jika diasumsikan bahwa pada saat $t \rightarrow \infty$ grafik $h_{2}(t)$ mengalami kenaikan cukup lambat dibanding dengan grafik $e^{-s t}$ maka $e^{-s t} h_{2}(t) \rightarrow 0$ untuk $t \rightarrow \infty$ bentuk Persamaan (4.8) dapat disederhanakan menjadi

$$
L\left(\frac{d h_{2}(t)}{d t}\right)=-h_{2}(0)+s H(s)
$$

Maka untuk mendapatkan solusi khususnya,

$$
L\left(\frac{d^{2} h_{2}(t)}{d t^{2}}\right)+L\left(2 \xi \omega \frac{d h_{2}(t)}{d t}\right)+L\left(\omega^{2} h_{2}(t)\right)=L\{0\} .
$$

Misalkan: $\frac{d^{2} h_{2}(t)}{d t^{2}}+2 \xi \omega \frac{d h_{2}(t)}{d t}+\omega^{2} h_{2}(t)=0$ dengan syarat awal $h_{2}(0)=0$, syarat batas $\frac{d h_{2}}{d t}(0)=1$, dan syarat peredam kritis $\alpha=1$, maka diperoleh:

$$
\begin{aligned}
& H(s)=\frac{1}{(s+\omega)^{2}} \\
& \Rightarrow L^{-1}\{H(s)\}=L^{-1}\left\{\frac{1}{(s+\omega)^{2}}\right\} \\
& \Rightarrow h_{p}=t e^{-\omega t}
\end{aligned}
$$

Jadi, solusi totalnya adalah jumlahan dari solusi umum dan solusi khusus.

$$
\begin{aligned}
& h_{t}=h_{2}(t)+h_{p} \\
& h_{t}=c_{1} e^{\left(-\xi \omega+\omega \sqrt{\xi^{2}-1}\right) t}+c_{2} e^{\left(-\xi \omega-\omega \sqrt{\xi^{2}}-1\right) t}+t e^{-\omega t}
\end{aligned}
$$




\section{Kasus Peredam Kritis $(\xi=1)$}

Solusi umumnya yaitu:

$$
h_{2}(t)=e^{-(\xi \omega) t}\left(c_{1}+t c_{2}\right)
$$

Persamaan (4.13) menyatakan tinggi air pada bejana $B_{2}$ saat $t$. yang berarti keadaan awal $B_{2}$ sama dengan nol. Nol artinya tidak ada air pada bejana $B_{2}$. Dengan $c_{1}$ dan $c_{2}$ adalah konstanta, yang nilainya kedua konstanta tersebut bergantung dari $h_{2}(0)$ dan $\frac{d h_{2}(0)}{d t}$, seperti yang diuraikan di bawah ini.

Misalkan $h_{2}(t)=e^{-(\xi \omega) t}\left(c_{1}+t c_{2}\right), h_{t}(0)=A_{2}, \quad \frac{d h_{2}(0)}{d t}=B_{2}$

Maka diperoleh $c_{1}$ dan $c_{2}$ adalah sebagai berikut

$$
\begin{aligned}
& c_{1}=A_{2} \\
& c_{2}=B_{2}+(\xi \omega) A_{2}
\end{aligned}
$$

3. Kasus Peredam Berkurang $(0<\xi<1)$

Solusi umumnya yaitu:

$$
h_{2}(t)=e^{-(\xi \omega) t}\left(c_{1} \cos \left(\left(\omega \sqrt{1-\xi^{2}}\right) t\right)+c_{2} \sin \left(\left(\omega \sqrt{1-\xi^{2}}\right) t\right)\right)
$$

Persamaan (4.11) menyatakan tinggi air pada bejana $B_{2}$ saat $t$. artinya keadaan mula-mula pada bejana $B_{2}$ adalah kosong dan laju bertambahnya tinggi air pada bejana $B_{2}$ adalah semakin tinggi peningkatan air.

Dengan $c_{1}$ dan $c_{2}$ adalah konstanta, yang nilainya kedua konstanta tersebut bergantung dari $h_{2}(0)$ dan $\frac{d h_{2}(0)}{d t}$, seperti yang diuraikan di bawah ini.

Misalkan

$$
\begin{aligned}
h_{2}(t) & =e^{-(\xi \omega) t}\left(c_{1} \cos \left(\left(\omega \sqrt{1-\xi^{2}}\right) t\right)+c_{2} \sin \left(\left(\omega \sqrt{1-\xi^{2}}\right) t\right)\right) \\
h_{2}(0) & =A_{2}, \quad \frac{d h_{2}(0)}{d t}=B_{2}, \text { maka diperoleh } c_{1} \text { dan } c_{2} \text { adalah sebagai berikut } \\
c_{1} & =A_{2} \\
c_{2} & =\frac{B_{2}+A_{2}(\xi \omega)}{\omega \sqrt{1-\xi^{2}}}
\end{aligned}
$$

Sehingga untuk $t \rightarrow \infty$ maka $h_{2}(t) \rightarrow 0$ dan $V_{2}(t) \rightarrow 0$, yang berartu untuk jangka waktu yang lama, maka tidak ada air pada bejana $B_{2}$.

Contoh Kasus (Julius Sigit Wicaksono, Pemodelan Matematika Pada Sistem Pembangkit Listrik Tenaga Air, h.77)

Misalkan diketahui $\xi=\frac{4}{2 \sqrt{13}}, \omega=\sqrt{13}$, keadaan mula-mula pada $B_{2}$ adalah kosong, dan laju bertambahnya air $B_{2}$ pada mulanya adalah 1. Bagaimanakah ketinggian dan volume air yang sesuai pada $B_{2}$ ? 
Penyelesaian:

$$
\begin{aligned}
& \frac{d^{2} h_{2}(t)}{d t^{2}}+4 \frac{d h_{2}(t)}{d t}+13 h_{2}(t)=0, \quad h_{2}(0)=0, \quad \frac{d h_{2}(0)}{d t}=1 \\
& h_{2}(t)=e^{-(\xi \omega) t}\left(c_{1} \cos \left(\left(\omega \sqrt{1-\xi^{2}}\right) t\right)+c_{2} \sin \left(\left(\omega \sqrt{1-\xi^{2}}\right) t\right)\right) \\
& h_{2}(t)=e^{-\left(\frac{4}{2 \sqrt{13}} \cdot \sqrt{13}\right) t}\left(c_{1} \cos \left(\left(\sqrt{13} \sqrt{1-\left(\frac{4}{2 \sqrt{13}}\right)^{2}}\right) t\right)+c_{2} \sin \left(\left(\sqrt{13} \sqrt{1-\left(\frac{4}{2 \sqrt{13}}\right)^{2}}\right) t\right)\right. \\
& h_{2}(t)=e^{-2 t}\left(c_{1} \cos (3 t)+c_{2} \sin (3 t)\right)
\end{aligned}
$$

Untuk memeperoleh nilai $c_{1}$ dan $c_{2}$ untuk $h_{2}(0)=A_{2}=0$ dan $\frac{d h_{2}(0)}{d t}=B_{2}=1$

$$
c_{1}=0 \text { dan } c_{2}=\frac{1+0\left(\frac{4}{2 \sqrt{13}} \sqrt{13}\right)}{\sqrt{13} \sqrt{1-\left(\frac{4}{2 \sqrt{13}}\right)^{2}}}=\frac{1}{3}
$$

Jadi, solusi umumnya adalah

$$
h_{2}(t)=e^{-2 t}\left(0 \cdot \cos (3 t)+\frac{1}{3} \sin (3 t)\right)=\frac{1}{3} e^{-2 t} \sin (3 t)
$$

Solusi khususnya adalah:

$$
\begin{aligned}
& H(s)\left(s^{2}+4 s+13\right)-h_{2}(0)(s+4)-\frac{d h_{2}}{d t}(0)=0 \\
& H(s)=\frac{1}{s^{2}+4 s+13}
\end{aligned}
$$

Untuk mengetahui akar-akarnya menggunakan rumus abc

$$
s_{1}=-2+3 i \text { atau } s_{1}=-2-3 i
$$

Untuk mencari solusi Persamaan diferensial asal,ubah $H(s)$ dari bentuk $s$ ke bentuk $t$ menggunakan invers Transformasi Laplace.

$$
\begin{aligned}
H(s) & =\frac{1}{(s+2)^{2}+3^{2}} \\
L^{-1}\{H(s)\}=L^{-1}\left\{\frac{1}{(s+2)^{2}+3^{2}}\right\} & \\
\Rightarrow L^{-1}\left\{\frac{1}{s^{2}+3^{2}}\right\} & =L^{-1}\left\{\frac{1}{3} \frac{3}{s^{2}+3^{2}}\right\} \\
& =\frac{1}{3} L^{-1}\left\{\frac{3}{s^{2}+3^{2}}\right\}
\end{aligned}
$$

sehingga, $h_{p}=e^{-2 t} \frac{1}{3} \sin (3 t)=\frac{1}{3} e^{-2 t} \sin (3 t)$

Jadi, solusi totalnya adalah

$$
h_{t}=h_{2}(t)+h_{p}
$$




$$
h_{t}=\left[\frac{1}{3} e^{-2 t} \sin (3 t)\right]+\left[\frac{1}{3} e^{-2 t} \sin (3 t)\right]=\frac{2}{3} e^{-2 t} \sin (3 t)
$$

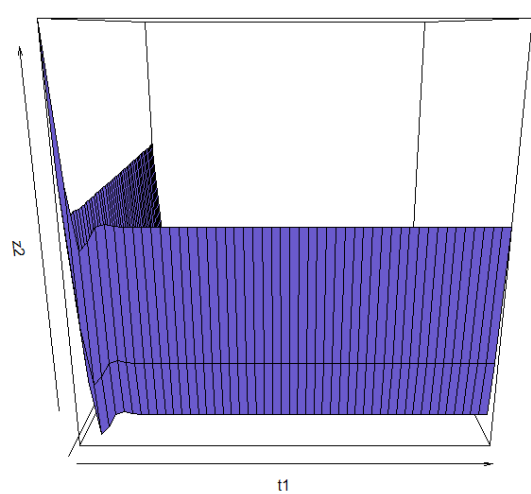

Gambar 4. Tinggi Air untuk Peredam Berkurang

\section{B. PEMBAHASAN}

Benda yang mengalami redaman berlebihan/Overdamped memiliki waktu yang sangat lama untuk kembali pada posisi setimbangnya ketika di berikan gaya atau hambatan. Karena gaya yang diberikan pada benda sangat besar. Pada gambar 4.1 menunjukan tinggi air untuk peredam berlebihan yang menyatakan volume air pada saat bejana $B_{2}$ adalah konstan yang bergantung dari $h_{2}(0)$ dan $\frac{d h_{2}(0)}{d t}$, waktu peningkatan air yang terjadi pada $B_{2}$ berbeda beda yang sesuai dengan laju awal bertambahnya tinggi air pada $B_{2}$ sehingga semakin besar laju awal pada $B_{2}$ maka semakin tinggi peningkatan air $B_{2}$.

Benda yang mengalami peredaman kritis/Criticallydamped biasanya langsung berhenti osilasi (benda langsung kembali ke posisi setimbangnya) ketika diberikan gaya, karena redaman yang dialaminya cukup besar. Pada gambar 4.2 menunjukan tinggi air untuk peredam kritis yang menyatakan volume air pada saat bejana $B_{2}$ adalah sama sehingga peningkatan laju perubahahan atau laju peningkatan volume air sama dengan laju awal pada $B_{2}$.

Benda yang mengalami Underdamped biaasanya melakukan beberapa osilasi sebelum berhenti. Karena redaman yang dialaminya tidak terlalu besar. Pada gambar 4.3 menunjukan tinggi air untuk peredam berkurang menyatakan volume air pada saat bejana $B_{2}$ adalah konstan yang bergantung dari $h_{2}(0)$ dan $\frac{d h_{2}(0)}{d t}$, waktu peningkan air yang terjadi pada $B_{2}$ berbeda beda yang sesuai dengan laju awal bertambahnya tinggi air pada $B_{2}$ sehingga semakin besar laju awal pada $B_{2}$ maka semakin tinggi peningkatan air $B_{2}$. Akibatnya peningkatan laju perubahahan atau laju peningkatan volume air sama dengan laju awal pada $B_{2}$. 


\section{KESIMPULAN}

Solusi persamaan diferensial pada sistem bejana dengan menggunakan metode Transformasi Laplace adalah sebagai berikut:

Penyelesaian solusi umumnya adalah

$$
h_{2}(t)=c_{1} e^{\left(-\xi \omega+\omega \sqrt{\xi^{2}-1}\right) t}+c_{2} e^{\left(-\xi \omega-\omega \sqrt{\xi^{2}}-1\right) t}
$$

Penyelesaian solusi khusus yang dilakukan dengan metode transformasi laplace adalah

$$
h_{p}=t e^{-\omega t}
$$

Penyelesaian solusi total dilakukan dengan menggabungkan solusi umum dan solusi khusus, sehingga diperoleh

$$
h_{t}=c_{1} e^{\left(-\xi \omega+\omega \sqrt{\xi^{2}-1}\right) t}+c_{2} e^{\left(-\xi \omega-\omega \sqrt{\xi^{2}}-1\right) t}+t e^{-\omega t}
$$

\section{DAFTAR PUSTAKA}

Asrijal. 2016. Aplikasi Metode Transformasi Laplace pada Dinamika Sistem Fisis-Massa Pegas dengan Shock Absorber, Makassar: FST UIN Alauddin Makassar.

Budi, Nugroho Didit. 2010. Persamaan Diferensial Biasa dan Aplikasinya Penyelesaian Manual dan Menggunakan Maple, Salatiga: Graha Ilmu.

Danang,Mursita. 2011. Matematika Lanjut untuk Perguruan Tinggi, Bandung:Rekayasa Sains.

Effendy, Nurul. 2008. Peredeman Osilasi Getaran Pada Suatu Sistem Dengan Pemodelan PegasDamper Menggunakan Kendali Logika Fuzzy. Jurnal Informatika.

Giancoli C. Douglas. 2014. Fisika. Prinsip dan Aplikasi Edisi ketujuh,Jilid 1". Jakarta:Erlangga.

Kementerian Agama RI.2012. Al-Qur'an dan Terjemahan, Bandung: Wali Oasis Terrace Recident.

Lee, Taehee. 2014. Int. Journal of Math. The Representation of Energy Equation by Laplace Transform. Vol. 8, no. 22 .

Marwan dan Said Munzir. 2011. Persamaan Diferensial, Yogyakarta:Graha Ilmu.

Murray, Spiegel R. 1983. Matematika Lanjut untuk Para Insinyur dan Ilmuwan, Jakarta:Erlangga.

Ratnasari. 2015. Fungsi Green yang dikonstruksi pada Persamaan Diferensial Liner Tak Homogen Orde- $n$. Jurnal Program Studi Matematika FST-UINAM.

Shihab, M.Quraish. 2002. Tafsir Al-Mishbah. Jakarta : Lentera Hati.

Sudarmono dan Elly, K. A. 2011. Kearifan Lokal Masyarakat Kabupaten Katingan Provinsi Kalimantan Tengah dalam Melestarikan Buah-Buahan Lokal Kalimantan di Kebun Raya Katingan. Prosiding Seminar Nasional Hari Lingkungan Hidup. 23 Juli 2011. Purwokerto: PPLH-LPPM UNSOED. ISBN 978-602-19161-0-0. hal 30-38.

Susilo,Anto. 2012.Simulasi Gerak Harmonik Sederhana dan Osilasi Teredam pada Cassy-E 524000. Indonesian Journal of Applied Physics. Vol. 2 No. 2.

Urzula,Ferdek. 2012. Journal of Theoritical and Applied Mechanics.Modelling and Analysis of A TwinTube Hydraulic Shock Absorber. Vol 2.

Wicaksono, Julius Sigit. 2007. Pemodelan Matematika pada Sistem Pembangkit Listrik Tenaga Air, Yogyakarta:FST Universitas Sanata Dharma. 